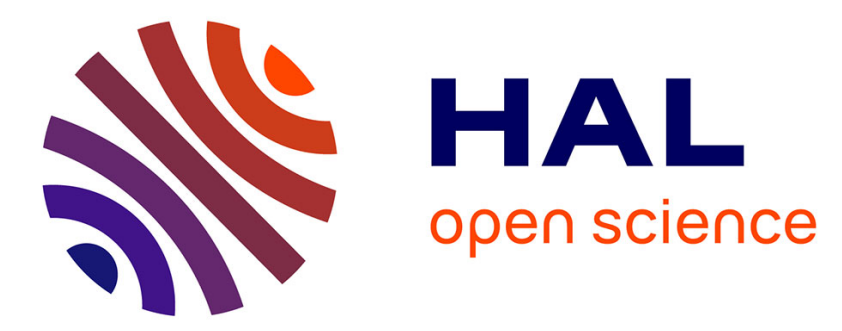

\title{
Acoustic and turbulent wavenumbers separation in wall pressure array signals using EMD in spatial domain
}

Vincent Grulier, Sebastien Debert, Jerome I. Mars, Marc Pachebat

\section{To cite this version:}

Vincent Grulier, Sebastien Debert, Jerome I. Mars, Marc Pachebat. Acoustic and turbulent wavenumbers separation in wall pressure array signals using EMD in spatial domain. ICASSP 2008 - IEEE International Conference on Acoustics, Speech and Signal Processing, Mar 2008, Las Vegas, Nevada, United States. pp.AE-P6.3. hal-00348772

\section{HAL Id: hal-00348772 \\ https://hal.science/hal-00348772}

Submitted on 21 Dec 2008

HAL is a multi-disciplinary open access archive for the deposit and dissemination of scientific research documents, whether they are published or not. The documents may come from teaching and research institutions in France or abroad, or from public or private research centers.
L'archive ouverte pluridisciplinaire HAL, est destinée au dépôt et à la diffusion de documents scientifiques de niveau recherche, publiés ou non, émanant des établissements d'enseignement et de recherche français ou étrangers, des laboratoires publics ou privés. 


\section{ACOUSTIC AND TURBULENT WAVENUMBERS SEPARATION IN WALL PRESSURE ARRAY SIGNALS USING EMD IN SPATIAL DOMAIN}

\author{
Vincent Grulier*, Sébastien Debert ${ }^{+}$ \\ ${ }^{*}$ GIPSA-Lab \\ Department Images-Signal \\ Rue de la Houille Blanche, BP 46, \\ 38402 Saint Martin d'Hères Cedex, France \\ jerome.mars@gipsa-lab.inpg.fr
}

\author{
Jérôme I. Mars* ${ }^{*}$ Marc Pachebat ${ }^{+}$ \\ ${ }^{+}$PSA-Peugeot-Citroën \\ Acoustics and Vibration R.D. \\ Route de Gisy, CC: VV013, \\ 78943 Vélizy-Villacoublay Cedex, France \\ marc.pachebat@mpsa.com
}

\begin{abstract}
Empirical Mode Decomposition (EMD) is a powerful "timefrequency" tool that is used here in the spatial domain to filter out at each instant, short scale wall pressure fluctuations measured by a linear microphone array beneath a boundary layer. A frequency over streamwise wavenumber representation is used to separate acoustic and turbulent energy: it is obtained by a classical spatial-correlogram which is performed either on original signals or on spatial EMD-filtered signals. It is shown how spatial EMD filtering reduces the spread of the convective energy due to the truncation effects and is tuned to improve the separation of the acoustical energy out of the turbulent energy.
\end{abstract}

Index Terms - Wavenumber filtering, Spatial EMD, Turbulent boundary layer, Acoustics

\section{INTRODUCTION}

Transportation vehicles generate exterior turbulent flows featuring fluctuating quantities either convected by the local mean velocity (associated to turbulent or aerodynamic energy in the following) or propagating along any direction in space at the speed of sound (acoustic energy). At car driving speed $U$ above $100 \mathrm{~km} / \mathrm{h}$, aerodynamic and acoustic wall pressure fluctuations on the vehicle both contribute to the interior noise. This because the vibroacoustic behaviour of solid structure like side windows acts like a wavenumber filter that strongly cut-out wave number associated to the turbulent energy. Thus, acoustic fluctuations produced by the flow must be known to predict interior car noise. Evaluation from wall pressure signals of this acoustic energy produced by a turbulent flow like a boundary layer (TBL) is still an issue as it could lay at least $20 \mathrm{~dB}$ below the turbulent energy. At a given frequency, aerodynamic and acoustic wave number ratio equals the Mach number which is about 0.1 in that particular case and this is used here to separate acoustic energy.
Wall pressure fluctuations are measured by a linear array of microphones beneath a TBL in an anechoic wind-tunnel. A frequency $(f)$ over streamwise wavenumber $\left(k_{x}\right)$ representation of the wall pressure is obtained by a classical spatialcorrelogram method. In practice, the truncation effects, associated with the finite span of the antenna, and the aliasing effects, due to the spatial undersamplig, scatters the convective energy in parts of the wavenumber-frequency plane where it is not physically expected. In this work, it is shown how the Empirical Mode Decomposition (EMD) (Huang et al. [1]), a powerful "time-frequency" method with many possibilities, helps to overcome these difficulties and is tuned to further improve the separation of the acoustical energy out of the turbulent energy. EMD is used here in a new and very simple manner. New because it is used along the spatial dimension on real data and simple because the task consists in filtering, at each instant, the small spatial fluctuations along the linear array by cutting-out some of the first spatial Intrisic Mode Functions (IMFs). For the sake of clarity, results obtained from the original signals (section 2) or from the EMD-filtered signals are presented for two cases : 1- the TBL fluctuations alone and 2- for the TBL combined with acoustic energy injected by an artificial acoustic source. They show that spatial EMD (sEMD) filtering is more efficient than classical filterings.

\section{EXISTING METHODS FOR WAVENUMBER SEPARATION: THE SPATIAL CORRELOGRAM}

Measurement are performed on a flat plate with mean flow velocity $U_{\infty}=40 \mathrm{~m} / \mathrm{s}$. An array of 61 holes covers $L=$ $0.314 \mathrm{~m}$ of the flat plate along the streamwise axis $O x$ (diam. $0.810^{-3} \mathrm{~m}$, spacing: $\left.\Delta x=5.2410^{-3} \mathrm{~m}\right)$. Each hole is connected via a small tube to a remote microphone and a long anechoic termination. The time signal of each remote microphone is corrected in amplitude and phase in order to obtain the pressure fluctuations at the wall surface ([2], [3]). 
Measured wall-pressure fluctuations $p(x, t)$ consists of 61 simultaneous spatial samples stored during $100 \mathrm{~s}$ at $25.6 \mathrm{kHz}$ sampling rate. In order to estimate wavenumber frequency spectrum $\Phi\left(k_{x}, f\right)$ of $p(x, t)$, a spatial correlogram method is used [4]. First, the cross-power spectra $S(r, f)$ are estimated using $N_{b l k}=2500$ blocks of $N_{s p l}=1024$ samples (Eq.1):

$S_{n}\left(r_{n}, f\right)=\frac{1}{N_{b l k}} \sum_{i=1}^{N_{b l k}} \sum_{q=1}^{N_{s p l}} p_{i}(x, t) p_{i}^{*}\left(x+r_{n}, t+\tau_{q}\right) e^{-j 2 \pi f \tau_{q}}$

where $p^{*}$ is the complex conjugate of $p$. The subscribed $n$ refers to the probe $n$. Then the wavenumber frequency spectra $\Phi\left(k_{x}, f\right)$ are obtained by a spatial Fourier transform on $S_{n}\left(r_{n}, f\right)$ (Eq.2):

$$
\Phi\left(k_{x}, f\right)=\sum_{n=1}^{N_{\text {prob }}} S_{n}\left(r_{n}, f\right) e^{-j k_{x} . r_{n}}
$$

where $N_{\text {prob }}$ is the number of probes. The modulus $\left|\Phi\left(k_{x}, f\right)\right|$ of the wavenumber frequency spectra is shown on Fig. 1 in $\mathrm{dB}$ scale (ref. $1 \mathrm{~Pa}^{2}$ ). Whatever its direction of propagation, all acoustic energy present in the wind-tunnel should be located inside a vertical cone delimited by $\pm c_{0} / 2 \pi$ slopes ( $c_{0}=340 \mathrm{~m} / \mathrm{s}$ is the sound velocity). On Fig. 1, the acoustic contribution is visible in this zone along a line the slope of which corresponds to the upstream position of the artificial source. The convective energy is displayed around a straight line with a $U_{\infty} / 2 \pi$ slope. Fig. 2 is identical to Fig. 1 but the

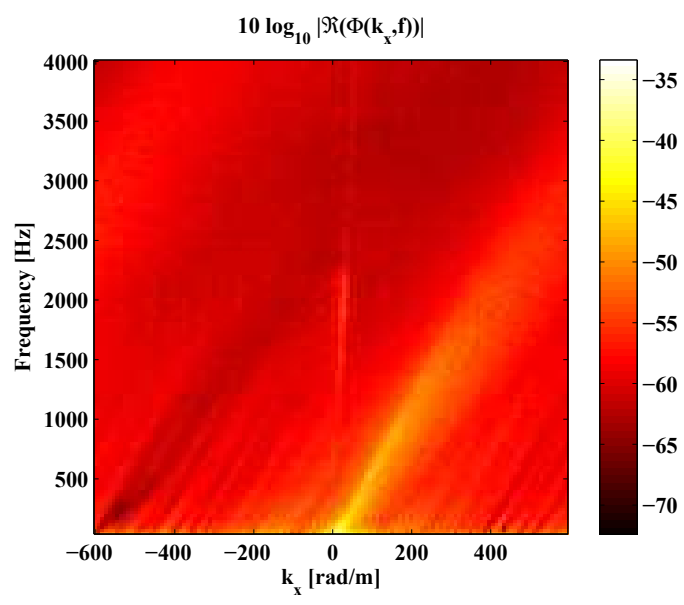

Fig. 1. Wavenumber-frequency representation of the wall pressure under the TBL plus an artificial acoustic source $(\mathrm{dB}$ ref. $1 \mathrm{~Pa}^{2}$ ).

acoustical source has been switched off during the measurement. Both figures 1 and 2 highlight two major effects: (a) the truncation effects due to the finite length of the antenna, dominant at $f<1500 \mathrm{~Hz}$ and characterized by the spread of the energy along the $k_{x}$ axis and (b) the aliasing of convective energy especially at high frequencies $(f>2000 \mathrm{~Hz})$ for $k_{x}<0$. We can notice that artificial acoustic energy cannot be visually located below $1200 \mathrm{~Hz}$ as it is buried in noise and convective energy (Fig. 1). No acoustic energy at all can be seen for the turbulent boundary layer alone (Fig.2).

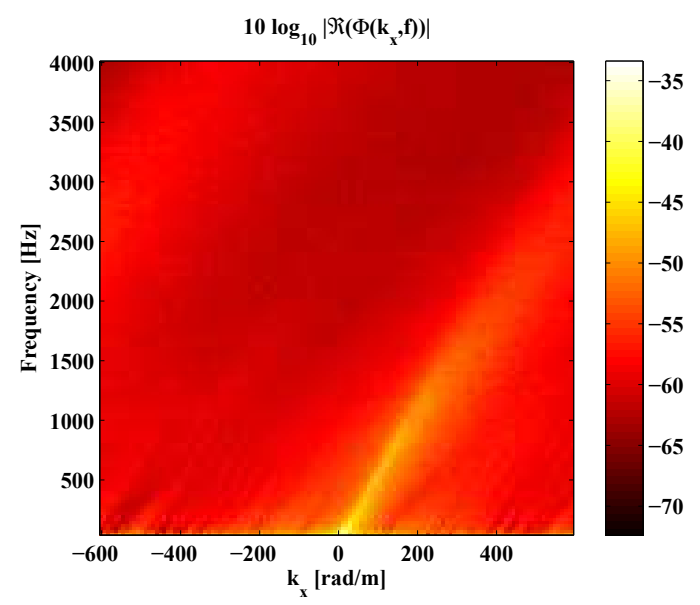

Fig. 2. Wavenumber-frequency representation of the wall pressure under the TBL (dB ref. $\left.1 \mathrm{~Pa}^{2}\right)$.

\section{WAVE NUMBER FILTERING OF WALL-PRESSURE FLUCTUATIONS USING EMPIRICAL MODE DECOMPOSITION}

In order to underline the presence of acoustic energy existing at low wavenumbers near the vertical axis $k_{x}=0$, the task is to decrease turbulent energy and improve the signalto-noise ratio by avoiding the truncation and aliasing effects. Thus we propose to perform a low-pass wavenumber filtering using the sEMD. Indeed, by performing a high vs. low (spatial) frequency discrimination, sEMD can be seen as a filtering [5]. The low-pass filtering is performed by sEMD [6] of the $N=2.5610^{6}$ instant realizations of the wall pressure spatial signal along the linear array (an example of the decomposition of one instantaneous spatial signal is shown on Fig. 3). The resulting IMFs number is varying according to instant between four and six IMFs plus a residual. A preliminary study shows that removing the two first IMFs at each instant does not cut-off the acoustic wavenumber energy whatever the number of IMFs computed. This is justified as follows: below $4000 \mathrm{~Hz}$, the acoustic wavenumbers $k_{x}=\omega / c_{0}$ are included between $\pm 74 \mathrm{rad} / \mathrm{m}$. Assuming that the zero crossings number $(\mathrm{ZxN})$ of an IMF is a rough estimation of its mean spatial frequency, we associate this $\mathrm{ZxN}$ to a wavenumber. The minimum $\mathrm{ZxN}$ of the two first IMFs is always superior to 13 (see table 1), and thus corresponds to a wavenumber always higher than $74 \mathrm{rad} / \mathrm{m}$ the maximum acoustic wavenumber. This ensures that removing the two first IMFs keeps the acoustic energy intact. 


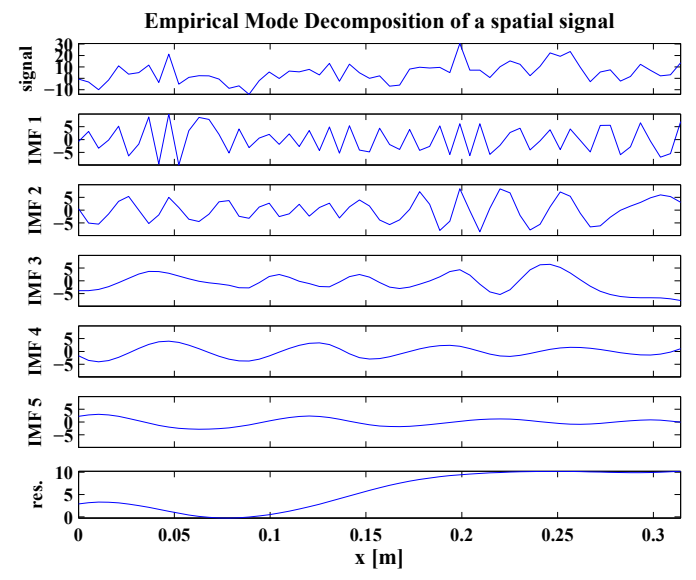

Fig. 3. Example of the sEMD of one spatial signal along the array at a given instant (signal, 5 IMFs and residual).

\begin{tabular}{|c|c|c|}
\cline { 2 - 3 } \multicolumn{1}{c|}{} & $\mathbf{Z x N}$ & Wavenumber \\
\hline 1st and 2nd IMF & {$[13-53]$} & {$[129.9-529.6]$} \\
\hline 3rd IMF to residual & {$[0-24]$} & {$[0-239.8]$} \\
\hline
\end{tabular}

Table 1. Zero Crossings Number $(\mathrm{ZxN})$ and Wavenumber $[\mathrm{rad} / \mathrm{m}]$ limit values [min.-max.] of calculated IMFs.

Results of sEMD processing on wall pressure fluctuations is shown on Fig. 4 and Fig. 5. Comparison between Fig. 1 and Fig. 4 shows that the expected low-pass filtering in the wavenumber domain is reached. Indeed, energy located out of the wavenumber domain between about $\pm 150 \mathrm{rad} / \mathrm{m}$ is considerably attenuated. This filtering is beneficial because it rejects noise associated with the truncation effects, notably the one which pollute the low wavenumbers (near $k_{x}=0$ ), where acoustical contribution is located. So low-pass sEMDfiltering leads to the enhancement of the acoustic signal-tonoise ratio. In particular, "acoustic line" is now visible in a [700-1100] Hz frequency range (Fig. 4). The sEMD-filtering deletes also the aliasing of the convective energy.

Fig. 5 compares before and after sEMD the results of the wavenumber-frequency spectrum at three frequencies. At $f=950 \mathrm{~Hz}$, energy level at low wavenumbers was globally lowered of about $3 \mathrm{~dB}$ after sEMD-filtering. This fact seems to be the consequence of the enfeeblement of the replicated convective patterns. Therefore the "acoustic peak" which was polluted with noise is now recovered and is also observed at $f=2900 \mathrm{~Hz}$. At $f=1950 \mathrm{~Hz}$, the maximum acoustic energy level is not altered by the sEMD-filtering, wich is not sufficient relative to the goal of this work but necessary. Moreover, the power of detection is widely intensified : acoustic peak gains about $5 \mathrm{~dB}$ in relation to the baseline.

On Fig. 6, the spatial-frequency representation of the wall pressure obtained from eq. 1 is shown. It is a good physical illustration of the separation of the two contributions with
sEMD-filtering. On the left, without sEMD-filtering, convective coherence length are clearly visible under $2500 \mathrm{~Hz}$. On the right, low-pass filtering removed the convective energy over $900 \mathrm{~Hz}$ : the acoustic signature, characterized by a greater coherence length, arises from background noise.

For the TBL alone, the acoustic contribution is still not visible after sEMD-filtering (see Fig. 7 and Fig. 8). However, the cuts at $f=950 \mathrm{~Hz}$ shows that the pressure level at low wavenumbers has been lowered of about $2 \mathrm{~dB}$, increasing the probability to find acoustic energy if it would exist at this level.

sEMD-filtering has proven that it was efficient in terms of separation and easy to use because it does not require sensible parameters to fix. Results given by classical low-pass filters defined in wavenumber or in frequency by a mask would be less convincing. Indeed, with these filters it is impossible to separate the acoustic and the convective contribution under the mask if they are mixed. This is the same problem with a $2 D k_{x} f$ filter. However, wavelet filtering could give similar results as the sEMD-filtering but its use is less convenient because it needs the choice of the wavelet type and its parameters.

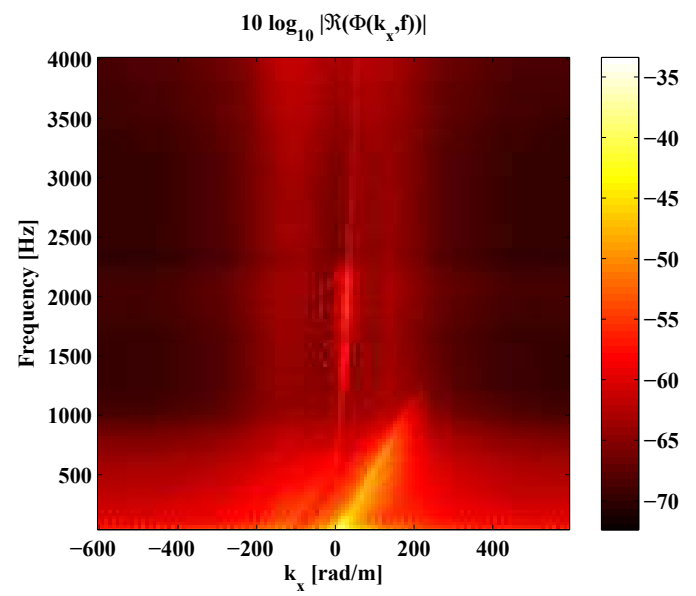

Fig. 4. Wavenumber-frequency representation of the sEMDfiltered wall pressure under TBL with acoustic source (dB ref. $\left.1 \mathrm{~Pa}^{2}\right)$.

\section{CONCLUSION}

A low-pass wavenumber filtering using spatial EMD is carried out before the spatial correlogram processing to enhance the separation of the acoustic and turbulent contributions to the flow-induced wall pressure. Results with and without sEMD pre-processing have shown the relevance of the method in terms of improvement of the acoustic signal-to-noise ratio when the acoustic energy is injected by an artificial acoustic source. Indeed, the sEMD-filtering is easy to use and very 


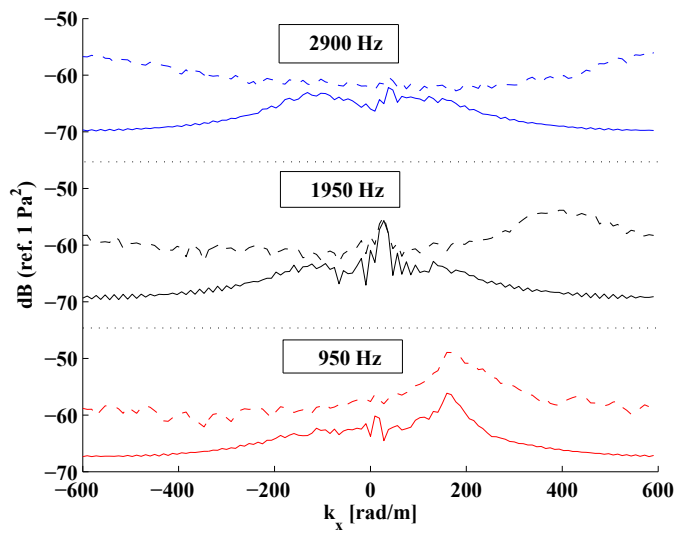

Fig. 5. Wavenumber representation at three frequencies of the wall pressure under TBL with acoustic source $\left(\mathrm{dB} r e f .1 \mathrm{~Pa}^{2}\right)$. Dash line : original signals, solid line : sEMD-filtered signals
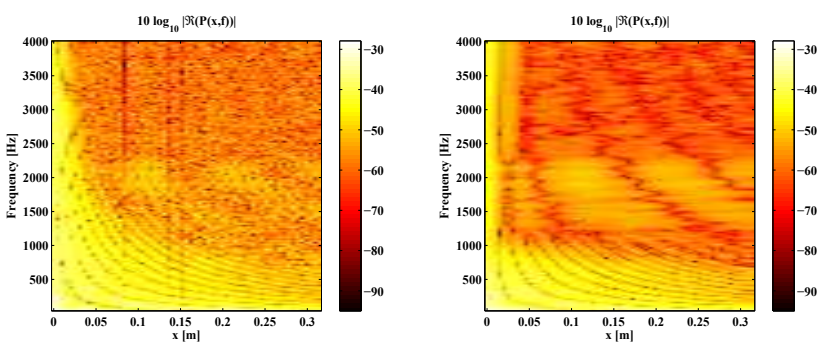

Fig. 6. Space-frequency representation of the wall pressure under TBL with acoustic source $\left(\mathrm{dB} r e f .1 \mathrm{~Pa}^{2}\right)$. Left: original signals. Right: sEMD-filtered signals.

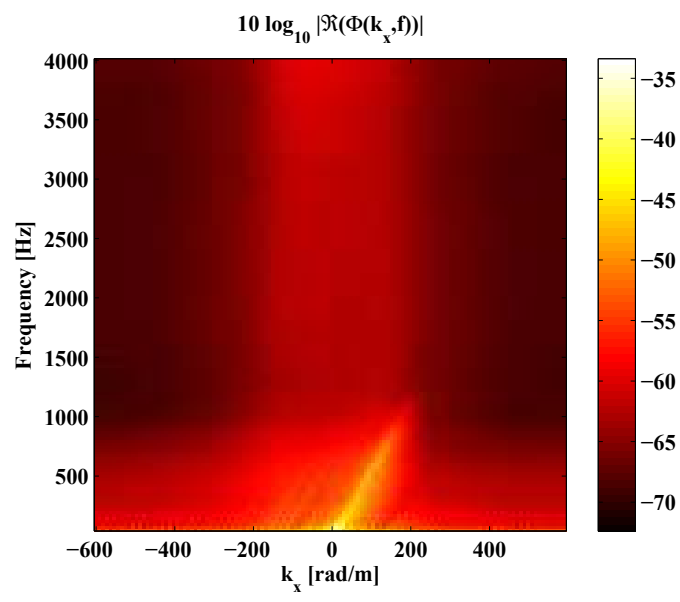

Fig. 7. Wavenumber-frequency representation of the sEMDfiltered wall pressure under TBL $\left(\mathrm{dB}\right.$ ref. $\left.1 \mathrm{~Pa}^{2}\right)$.

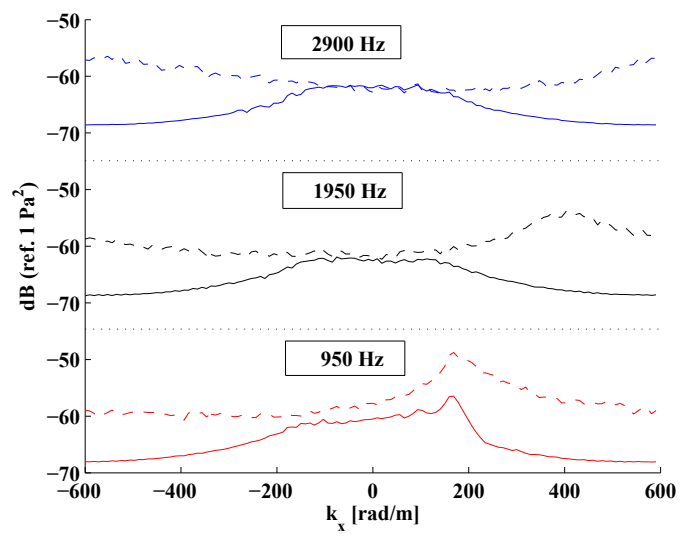

Fig. 8. Wavenumber representation at three frequencies of the wall pressure under TBL $\left(\mathrm{dB} r e f .1 \mathrm{~Pa}^{2}\right)$. Dash line : original signals, solid line : sEMD-filtered signals

helpful in relation to classical filtering because it decreases the turbulent energy and its associated artifacts without altering the acoustic energy.

In the future the processings performed here could be tested via a $x-y$ bidimensional extension on experimental cases where the flow-induced acoustic production is supposed to be more important as a step under flow.

\section{REFERENCES}

[1] N. E. HUANG, Z. SHEN, S. R. LONG, M. C. WU, H. H. SHIH, Q. ZHENG, N.-C. YEN, C. C. TUNG, and H. H. LIU, "The empirical mode decomposition and the hilbert spectrum for nonlinear and non-stationary time series analysis," The Royal Society of London, vol. 454, pp. 903-995, 1998.

[2] B. ARGUILLAT, D. RICOT, G. ROBERT, and C. BAILLY, "Measurements of the wavenumberfrequency spectrum of wall pressure fluctuations under turbulent flows," in 11th AIAA/CEAS Aeroacoustics Conf. Monterey CA. AIAA Paper, 2005, pp. 1-18.

[3] S. DEBERT, M. PACHEBAT, V. VALEAU, and Y. GERVAIS, "Experimental wave number separation of wallpressure fluctuations beneath a turbulent boundary layer," in Inter. Congress on Acoustics Madrid, 2007.

[4] R. GARELLO, Bi-dimensional Signal Analysis (Digital Signal and Image Processing series), ISTE, 2007.

[5] P. FlANDRIN, G. RILLING, and P. GONCALVES, "Empirical mode decomposition as a filter bank," IEEE Signal Processing Letters, vol. 11, pp. 112-114, 2004.

[6] http://perso.ens-lyon.fr/patrick.flandrin/emd.html. 